\title{
Report of the Editors of the American Political Science Review, 2011-2012
}

John Ishiyama, Lead Editor for the University of North Texas APSR Editorial Team

W e report here the journal's operations during the year from July 1, 2011, to June 30 , 2012, (when the Review was headed by the UCLA editorial team) and the period July 1, 2012 to January 1, 2013, or the first six months when the University of North Texas team has been at the helm. In this report, we also summarize the transition process from UCLA to the University of North Texas (UNT).

Continuing a tradition established by our predecessors, we wish to express our great thanks to the APSA, Past President Powell, President Mansbridge, President-Elect Aldrich, the Staff, the Council, and the Publications Committee, as well as to Cambridge University Press for their support and guidance during this transition process. We are particularly grateful to Presidents Powell and Mansbridge and APSA Executive Director Michael Brintnall, APSA Director of Communications and Publishing Polly Karpowicz, and Mark Zadrozny and the Cambridge University Press team for their vital help in making the transition process from UCLA to UNT a smooth one. Finally, our very special thanks to Ron Rogowski and his team at UCLA (and in particular, the Managing/Senior Editor at UCLA, Joseph Riser) for making this transition an especially easy one. It has been a real pleasure to work with their team during this process.

We are very excited about the highly skilled individuals we have hired to fill both the Managing/Senior Editor and the newly created Assistant Managing Editor/Post Doctorate positions. Our Managing/Senior Editor is Meagan Williams who began her position in June 2012. Meagan brings an abundance of experience as a managing editor and working with the Editorial Manager software. She also holds a Masters Degree in political science. Our Assistant Managing Editor/Postdoctoral Fellow is Dr. Ramesh Sharma, who completed his $\mathrm{PhD}$ in political science at the University of Kentucky this past fall. He is a specialist on Ameri- can politics and particularly political behavior. He spent time as the lead editorial assistant of the journal Political Behavior and is very familiar with the Editorial Manager system. Our graduate editorial assistants are fully trained and familiar with the Editorial Manager software and have performed quite admirably in the six months since we have taken over the reins of the Review.

In sum, our editorial team comprises:

John Ishiyama, Lead Editor

Marijke Breuning, Editor

Steven Forde, Editor

Valerie Martinez-Ebers, Editor

Meagan Williams, Managing/Senior Editor

Ramesh Sharma, Assistant Managing Editor/Postdoctoral position

Jeremy Backstrom, Graduate Editorial Assistant

Benjamin Gross, Graduate Editorial Assistant

Nicholas Higgins, Graduate Editorial Assistant

Tatyana Kelman, Graduate Editorial Assistant

Anna Pechenina, Graduate Editorial Assistant

Members of our editorial board have helped us with their advice on more than a few submissions and have served as "guest editors" on UNT-connected submissions that might otherwise raise issues of conflict of interest. We would especially like to thank Larry Dodd of the University of Florida for yeoman's work as a guest editor. We also want to thank all of the authors who submitted their papers for consideration in the past year to both the UCLA and UNT teams and the referees who reviewed them. In particular, without the talented work of authors and the referees' commitment of time and effort in service of the profession, there simply would be no Review. Our entire discipline owes you a debt of gratitude, so thank you.

\section{TRANSITION PROCESS}

The transition process from UCLA to UNT was remarkably smooth, thanks in no small part to Ron Rogowski and the UCLA editorial team, and their Managing/Senior Editor Joseph Riser. Per agreement with the UCLA team, the UCLA team processed all incoming manuscripts prior to July 1, 2012. The UNT team took over processing incoming manuscripts on July 1 and after. The UCLA team continued to process all submissions they began (including revise and resubmits) until October 15, 2012, after which responsibility for finishing up processing passed to the UNT team. The UCLA team was responsible for the November 2012 issue. The first issue for which the UNT team was responsible was the February 2013(Volume 107 No. 1) issue. However, 107.1 included a number of "legacy" manuscripts, so much of the credit for this issue lies with the UCLA team.

During the transition from 2011-2012 the UNT editorial team also made a concerted outreach effort to increase the diversity of submissions, particularly from fields that have been less represented in the Review. This involved individual editor visits and the conduct of workshops at numerous professional conferences in the United States and abroad in an effort to appeal to political scientists who may have felt left out by the Review. We were hopeful that by engaging in such outreach efforts, submissions from fields such as international relations would increase, for instance, and there would be a greater diversity of submissions in terms of field and approach, as well as in terms of other indicators.

\section{SUBMISSIONS AND PROCESSING}

\section{Number of Submissions}

In terms of number of submissions, for 2011-12, the UCLA team reports that as with their first (2007-08), submissions spiked in their final year. In fact, that year (July 1, 2011 through June 30, 2012) recorded the second highest total for "new" APSR 
Table 1

\section{Submissions per Year}

NUMBER OF SUBMISSIONS

\begin{tabular}{lll}
\cline { 2 - 3 } YEAR & Total & New \\
\hline July 2012- & $\mathbf{5 4 9}$ & $\mathbf{4 8 9}$ \\
January 2013 & $\mathbf{8 4 6}$ & $\mathbf{7 6 1}$ \\
$\mathbf{2 0 1 1 - 2 0 1 2}$ & 779 & 685 \\
2010-2011 & 770 & 677 \\
$2009-2010$ & 757 & 693 \\
$2008-2009$ & 829 & 778 \\
$2007-2008$ & 619 & 543 \\
$2006-2007$ & &
\end{tabular}

submissions (761) under the leadership of the UCLA editorial team. When revisions are also factored in, 2011-2012 represents the highest total number of papers handled in any 12-month period (846). Despite that record number, however, and despite the almost inevitable slight uptick in time from receipt to editor assignment, time from receipt to first decision still declined slightly in 2011-12 in comparison to the previous year.

In the first six months of operations under the UNT editorship (July 2012January 2013) we received 489 original submissions (or 549 total submissions including revise and resubmits left over from the previous team), or approximately 2.67 original submissions per day. If we extrapolate this out over 365 days, the current rate suggests about 975 submissions for 2012-2013 (although we believe that this rate may ease in the coming months). As of January 1, 2013 we invited 2,530 reviewers, 1,160 of whom accepted, 643 declined. The remaining reviewers were either withdrawn as reviewers, or we are awaiting a response for papers currently under review. Thus $64.3 \%$ agreed to review when requested.

\section{Turnaround Times}

We continue the trend of reducing the number of days from first receipt of a submission to first decision (table 2). As indicated in table 2, despite the uptick in submissions processed by the UCLA team from 2011-12, turnaround times decreased from 70.9 days on average to 68.9 days. Although the data is somewhat limited in that it only covers half a year and many things can change, during the first six months at the helm, the UNT team has reduced the turnaround time further to an average of 41.9 days. One of our primary goals was to shorten the editorial assistant vetting and co-editor reviewer assignment time. Our editorial assistants have been very diligent in processing manuscripts quickly, and we have endeavored to be as quick as possible in reviewer assignment times. We have also engaged in the practice of directly contacting late reviewers to expedite the review process, although our reviewers have been very prompt in completing their reviews, 34 days on average. Indeed, the lion's share of the credit in reducing turnaround times lies with the efficiency of our editorial assistants and of our reviewers.

\section{Mix of Submissions}

In terms of the mix of the submissions (see table 3a) during the period 2011-2012 the distribution of submissions changed only slightly. From 2011 to2012, there was a slight uptick in submissions from the American politics field (from $20 \%$ in $2010-$ 2011 to $23 \%$ in 2011-2012), but the percentages for the other subfields remained virtually the same.

For the six months under the leadership of the UNT team, the percentages are generally consistent with past patterns. Categorized by disciplinary subfield, the papers we received from July 2012 to January 2013 are also reported in table 3 a. The distributions are consistent with past distributions in previous APSR reports. The largest proportion of manuscripts continues to be from the comparative politics field (30\% in the past six months, compared to same proportions in the previous two years) with a small decline in the proportion manuscripts from American politics $(20 \%$ in the past six months compared to $23 \%$ in the previous year). The biggest increase (and in our view a most encouraging development given our stated goal of number of increasing the diversity of submissions) is the jump in submission from the international relations field, from $17 \%$ in $2011-2012$ to $20 \%$ currently. This is a most encouraging development. Submissions from normative theory, formal theory, methods and race, ethnicity, and politics remain consistent with past submission patterns.

During 2011-2012, in terms of the mix of submissions by approach, the patterns of submissions are also consistent with past patterns. The largest proportion continues to be quantitative (53.0\%) and the percentages for the other fields remained consistent when comparing the last year under the UCLA team with previous years. The one exception was the decline in submissions that used interpretive or conceptual approaches, but much of that was due to the addition of another category (qualitative and/or empirical) that was added by the UCLA team in their last year.

For the past six months under the UNT team the mix of submissions is very similar to the past patterns. There has been a slight decline in formal and formal and quantitative approaches, but increases in small $\mathrm{N}$, interpretive/conceptual, and qualitative and/or empirical. Overall, in the past six months, formal, quantitative, and formal and quantitative submissions constitute $68 \%$ of all submissions in comparison to the $74 \%$ of all submissions in 2011-12 and the average of $72 \%$ of all submissions from $2008-12$. We take these data as a positive sign in terms of our stated goal of diversifying the pool of submissions sent to the Review.

In addition to traditional indicators of the diversity of submissions that have appeared in past reports, we have also collected data on two other indicators of diversity during the period July 2012January 2013-gender of first author of the submission and national location of first author of the submission. These data were not collected by previous editorial teams.

Table 2

Elapsed Time (Avg. No. of Days) in Review Process, 2010-2012

\begin{tabular}{lccc} 
PHASE OF REVIEW PROCESS & $\begin{array}{c}\text { JULY 2012- } \\
\text { JANUARY 2013 }\end{array}$ & 2011-2012 & 2010-2011 \\
\hline From receipt to editor assignment & 2.5 & 12.2 & 9.3 \\
From editor assignment to first reviewer assigned & 0.9 & 7.4 & 10.6 \\
From editor assignment to first decision & 39.3 & 49.3 & 51.0 \\
From receipt to first decision & 41.9 & 68.9 & 70.9
\end{tabular}




\section{Distribution of New Papers Submitted, 2011-2012 (\%)}

FIELD

\begin{tabular}{|c|c|c|c|c|c|c|c|c|}
\hline YEAR & $\begin{array}{c}\text { American } \\
\text { Politics }\end{array}$ & $\begin{array}{c}\text { Comparative } \\
\text { Politics }\end{array}$ & $\begin{array}{c}\text { International } \\
\text { Relations }\end{array}$ & $\begin{array}{c}\text { Normative } \\
\text { Theory }\end{array}$ & $\begin{array}{l}\text { Formal } \\
\text { Theory }\end{array}$ & Methods & $\begin{array}{l}\text { Race, Ethnicity } \\
\text { \& Politics }\end{array}$ & Other \\
\hline July 2012-January 2013 & 20 & 30 & 20 & 17 & 6 & 3 & 3 & 1 \\
\hline 2011-2012 & 23 & 30 & 17 & 16 & 7 & 3 & 4 & 1 \\
\hline 2010-2011 & 20 & 30 & 17 & 17 & 6 & 3 & 4 & 3 \\
\hline 2009-2010 & 23 & 29 & 16 & 18 & 6 & 4 & 3 & 2 \\
\hline 2008-2009 & 25 & 22 & 16 & 15 & 8 & 3 & 3 & 8 \\
\hline 2007-2008 & 26 & 21 & 17 & 14 & 7 & 4 & 3 & 8 \\
\hline 2006-2007 & 31 & 31 & 15 & 15 & 5 & 3 & n.a. & n.a. \\
\hline
\end{tabular}

Table $3 b$

Distribution of New Papers Submitted, 2011-2012 (\%)

APPROACH

\begin{tabular}{|c|c|c|c|c|c|c|c|}
\hline YEAR & Formal & Quantitative & $\begin{array}{l}\text { Formal and } \\
\text { Quantitative }\end{array}$ & Small N & $\begin{array}{l}\text { Interpretive/ } \\
\text { Conceptual }\end{array}$ & $\begin{array}{l}\text { Qualitative and/ } \\
\text { or Empirical }\end{array}$ & Other \\
\hline July 2012-January 2013 & 7 & 53 & 8 & 1 & 22 & 7 & 2 \\
\hline 2011-2012 & 9 & 53 & 12 & $<1$ & 20 & 5 & $<1$ \\
\hline 2010-2011 & 8 & 50 & 10 & 3 & 29 & n.a. & $<1$ \\
\hline 2009-2010 & 11 & 49 & 12 & 1 & 26 & n.a. & 1 \\
\hline 2008-2009 & 12 & 49 & 13 & 2 & 23 & n.a. & 1 \\
\hline 2007-2008 & 14 & 49 & 8 & 2 & 25 & n.a. & 2 \\
\hline 2006-2007 & 11 & 55 & 4 & 2 & 24 & n.a. & 4 \\
\hline
\end{tabular}

Thus far, 373 of 487 manuscript first authors (76\%) during this period were men, and 114 were women (24\%) (two manuscripts could not be determined in terms of gender). Although we believe that this is progress, this is still lower than the estimated $32 \%$ of the APSA membership that is comprised of women. Further, approximately $34 \%$ of first authors of submitted manuscripts during the six months under the UNT editorial team were based in non-US institutions, an encouraging sign. We are hopeful to improve the diversity of submissions on all dimensions and will continue to monitor trends in terms of gender and international authorship.

\section{Outcomes}

Table 4 reports the outcome of the first round of the review process both for the year 2011-2012 and the past six-month period (as well as previous years for comparative perspective). For the past year under the leadership of the UCLA team the proportion of summary rejects and inappropriate submissions (both without review), the proportion of rejects after reviews, conditional accepts, and accepts after first round, were very consistent with percentages reported in the previous years.

Continuing the practice of our predecessors we have made use of summary rejection to relieve "reviewer fatigue" and to remove from consideration submissions that would most surely not survive the usual review process. Over the first six months, we made 396 decisions. In comparison with period 2011-2012 we have increased the percentage of summary rejects in the first six months under the UNT editorial team to nearly $24 \%$ of the total (up from $20 \%$ previously). However, our proportion of reject after reviews is lower than the previous years (although comparable to 2009-2010), and the

Table 4

\begin{tabular}{lcccc} 
Outcome of First Round of the Review Process (\%) \\
$\begin{array}{l}\text { JULY 2012- } \\
\text { JANUARY 2013 }\end{array}$ & $\mathbf{2 0 1 1 - 2 0 1 2}$ & $\mathbf{2 0 1 0 - 2 0 1 1}$ & $\mathbf{2 0 0 9 - 2 0 1 0}$ \\
OUTCOME & 1.7 & 1.1 & 0.8 & 1.0 \\
\hline Withdrawn & 23.8 & 19.9 & 20.7 & 20.4 \\
$\begin{array}{l}\text { Inappropriate submission and } \\
\text { Summary reject (without reviews) }\end{array}$ & 64.2 & 73.0 & 72.2 & 69.6 \\
Reject after reviews & 9.3 & 5.3 & 5.7 & 8.2 \\
Invite R\&R & 0.8 & 0.7 & 0.6 & 0.8 \\
Conditional accept & 0.1 & 0.1 & 0.0 & 0.0 \\
Accept & & & & \\
\hline
\end{tabular}


Table 5 a

Distribution of Papers Accepted-by FIELD, 2011-2012 (\%)

FIELD

\begin{tabular}{cccccc}
\hline American Politics & $\begin{array}{c}\text { Comparative } \\
\text { Politics }\end{array}$ & $\begin{array}{c}\text { International } \\
\text { Relations }\end{array}$ & $\begin{array}{c}\text { Normative } \\
\text { Theory }\end{array}$ & $\begin{array}{c}\text { Formal } \\
\text { Theory }\end{array}$ & $\begin{array}{c}\text { Race, Ethnicity } \\
\text { and Politics }\end{array}$ \\
\hline 21 & 33 & 7 & 19 & 10 & 5 \\
\hline
\end{tabular}

Table $5 b$

Distribution of Papers Accepted-by APPROACH, 2011-2012 (\%)

APPROACH

\begin{tabular}{ccccccc}
\hline Formal & Quantitative & $\begin{array}{c}\text { Formal and } \\
\text { Quantitative }\end{array}$ & Small N & $\begin{array}{c}\text { Interpretive/ } \\
\text { Conceptual }\end{array}$ & $\begin{array}{c}\text { Qualitative and/ } \\
\text { or Empirical }\end{array}$ & 0ther \\
\hline 12 & 48 & 14 & 2 & 19 & 5 & 0
\end{tabular}

percentage invited to revise and resubmit is higher than in previous years (although comparable to 2009-2010). These differences are largely due, in our view, to our higher summary reject rate and our decision as an editorial team to avoid inviting "de novo" resubmissions (or "reject and resubmit") which was a practice of previous editorial teams. Rather, we either reject or invite to revise and resubmit (and not "reject and resubmit"). This is consistent with the practice of other major journals, and we believe that avoiding granting de novo resubmissions is generally a wise practice that we will continue.

Tables 5a and $5 \mathrm{~b}$ report outcomes by accepted manuscripts by field and approach. In these tables we only report the data for 2011-2012 for the distribution of accepted manuscripts and not for the period July 2012-January 2013 because it is entirely too early to report on accepted manuscripts, simply because we have not accepted that many. We will have a better picture on progress on outcomes for our next annual report in 2014.

As in previous years, almost all of the papers accepted in 2011-2012 (85\%) had been initially submitted in a prior year. Hence it is more accurate to compare a given year's acceptances with the prior year's submissions. Papers accepted by field showed a fairly large decline in "American" (from 29\% to $21 \%$ ) and international relations (from $12 \%$ to $7 \%$ ). On the other hand, acceptances rose in comparative (from $25 \%$ to $33 \%$ ) and methods (from o\% to $5 \%$ ). Normative theory and race, ethnicity, and politics were almost unchanged during this period.

As indicated in table $5 \mathrm{~b}$, the percentage of formal, quantitative, and formal and quantitative acceptances continued to decline slightly but, taken together, continued to constitute three-quarters of all papers accepted from 2011 to 2012.

\section{Visibility}

Thanks largely to the efforts of the UCLA team, the Review remains the topranked journal in political science with a Thompson-Reuters Impact Factor (IF) score in 2011 of 3.05, making it again the top-ranked journal in political science The Review's five-year impact factor, at 3.759 in 2011, is fourth behind Political Analysis (5.402), Public Opinion Quarterly (4.02), and American Journal of Political Science (3.941), which is a slight decline from past years where the Review ranked second only to Political Analysis. We believe, however that this is largely a temporary blip and that the Review will recover its position soon.

\section{Future Plans}

In our continuing effort to connect with various constituencies in our discipline (to increase the diversity of submissions) we will continue the outreach efforts that we began during this past transition year. Over the past year, fifteen (15) conferences and professional meetings that host a great many political scientists have been attended by at least one of the co-editors.
We have addressed either the leadership of these organizations, the organized sections, or the caucus group of political scientists have been attended by at least one of the co-editors. We discussed our strategic goals and welcomed their suggestions and input. These meetings included many that one or more of the editors normally attend, so that we will likely continue our outreach efforts over the course of tenure as APSR editors. In 2013, we are scheduled to make additional outreach visits to a number of national and international conferences, workshops, and meetings to further broaden our outreach efforts.

Finally, as follow up to the last annual report, it is worth noting that we will continue the management model pioneered successfully by the UCLA team, namely (a) multiple editors are necessary to handle both the volume and the variety of submissions. (b) With modern technology, the multiple editors need not be from the same institution (but it certainly helps). (c) A lead editor is needed to provide coherence and continuity. (d) The co-editor model, in which the entire group considers papers before their final acceptance, pays large benefits in quality and readability of the pieces that appear in the Review.

Thank you very much for the opportunity to serve the association and our discipline, and we remain grateful for the trust and support of our colleagues. We welcome your comments and any suggestions as we proceed. 